Dušanka Zvekić-Dušanović*

UDC 811.163.41'367

Filozofski fakultet

DOI: $10.19090 /$ gff.2018.1.453-466

Univerzitet u Novom Sadu

\title{
KONDICIONALNE KONSTRUKCIJE S VEZNIKOM AKO I GLAGOLOM HTETI U PROTAZI**
}

$\mathrm{U}$ radu se analiziraju kondicionalne rečenice s veznikom ako u kojima se u funkciji predikata protaznog dela pojavljuje složeni predikat s modalnim glagolom hteti. Uočeno je da je u takvim rečenicama često i predikat apodoze modalno obeležen; ostvaruju se modalni pokazatelji podsticaja ili mogućnosti. Pod podsticajem se podrazumevaju različiti indikatori obaveze, nužnosti, potrebe, poželjnosti da se ostvari situacija označena dopunom. Tipična struktura za ovaj semantički model predstavljena je glagolom morati: ako hoće $X$, mora $Y$. U modalne indikatore mogućnosti ubrajaju se različita sredstva za iskazivanje dozvole, sposobnosti, sticaja okolnosti da se ostvari situacija označena dopunom. Za ovakvu semantičku kombinaciju tipičan je model s modalnim glagolom moći: ako hoće $X$, može $X$.

Ključne reči: srpski jezik, kondicionalne konstrukcije, uslovne rečenice, veznik ako, modalnost, modalni glagoli.

\section{UVOD}

1. Predmet ovog rada jesu kondicionalne konstrukcije u kojima govornik polazi od pretpostavke da postoji htenje, volja, želja subjekta za ostvarivanjem neke situacije i povodom toga iznosi svoj stav o potrebi ostvarenja neke druge situacije da bi se željena ispunila ili o mogućnosti ostvarenja željene situacije. Predikat protaznog dela ovakvih kondicionalnih rečenica predstavljen je modalnim glagolom hteti i dopunom, pri čemu dopuna referiše o situaciji željenoj od strane subjekta. U apodoznom delu se, u tom slučaju, najčešće javljaju modalne strukture: 1) one kojima se iskazuje neka druga situacija koju je neophodno/poželjno ostvariti da bi se ostvarila željena, ili 2) one kojima se iskazuje mogućnost ostvarivanja željene situacije. Ovakvi apodozni predikati mogu se realizovati pomoću tipičnih predstavnika značenja nužnosti (glagola morati) i mogućnosti (glagola moći):

\footnotetext{
*dusazd@gmail.com

** Rad je nastao u okviru projekta Sintaksička, semantička i pragmatička istraživanja standardnog srpskog jezika (178004), koji finansira Ministarstvo prosvete, nauke i tehnološkog razvoja Republike Srbije.
} 
1) ako hoće $X$, mora $Y$;
2) ako hoće $X$, može $X$.

Ovaj tip klauze pripada realnim uslovnim klauzama, kojima se iskazuje ostvarljiv i aktuelan uslov (Piper-Klajn, 2013: 518). Karakteriše ga pojavljivanje indikativa i u zavisnoj i u upravnoj klauzi, a u upravnoj se može ostvariti i glagol u imperativu. Realne uslovne klauze M. Ivić opisuje prema semantičkom principu, tj. kao tip u kojem ,govorno lice ne zna da li postoji (da li je postojala, odnosno da li će postojati) radnja imenovana tim predikatom, pa njenim postojanjem uslovljava ostvarivanje onoga što je saopšteno apodozom" (Ivić, 2008: 205-206). Rečenicama s realnouslovnim veznicima detaljno se u novijoj lingvističkoj literaturi bavi M. Kovačević (2013). Rečenice s veznicima ako i ukoliko razvrstava na osnovu glagolskog oblika u predikatu uslovne klauze, prihvatajući klasifikaciju po kojoj se, „prema vremenu važenja, uslovi mogu podeliti na: (1) budući uslov, (2) sadašnji uslov, (3) prošli uslov i (4) svevremenski uslov" (Stanojčić-Popović, 2002: 320). Među primerima koje autor navodi nema onih s modalnim glagolom hteti; međutim, zabeleženi su primeri s glagolom bliske semantike - želeti (Kovačević, 2013: 13):

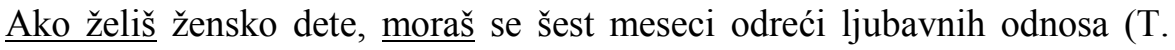
Ašić, 10); [...] ne smeju da osvoje ni bod manje od Grka u utorak uveče ukoliko žele direktno u Brazil (Večernje novosti, 13. 10. 2013, 39); I zato roditelji, ako zaista želite da vaša deca ostanu ovde, a ne da grade karijere po belom svetu, učite decu da pripadaju ovom podneblju (Politika, 5. 10. 2013, 18).

Ono što smatram značajnim pokazateljem ovih primera jeste činjenica da su i apodozni predikati modalno obeleženi; pojavljuju se modalni glagoli morati i smeti, kao i imperativ.

Za potrebe ovoga rada pregledan je Korpus savremenog srpskog jezika i zabeleženo je 645 primera s protaznim predikatom hteti (u prezentu) i dopunom. Od toga se čak u $392(60,7 \%)$ primera u apodozi javlja modalni indikator. ${ }^{1}$

\footnotetext{
${ }^{1}$ Iako veoma zastupljene u korpusu (26,3\% od ukupnog broja primera s prezentom glagola hteti u protazi), ovom prilikom se neće razmatrati rečenice tipa: On je dobar poznavalac književnosti, ako hoćete i vrhunski stručnjak (PCJ); On je dobar pisac, ako hoćete i stilista (PCJ). Njihova je karakteristika da realizacija sadržaja upravne klauze nije uslovljena realizacijom sadržaja zavisne klauze. One se mogu svrstati u klasu tzv. retoričkih kondicionala (up. Moskovljević Popović, 2018).
} 
$\mathrm{U}$ analizi je fokus na apodoznom delu kondicionalne konstrukcije. Prikazuju se različita leksička i sintaksička modalna sredstva koja se ostvaruju u upravnom delu i precizira se njihova semantika.

\section{ANALIZA \\ 1. Apodozni predikat sa značenjem podsticaja}

1.1. Prilikom iskazivanja nužnosti, podsticaja jakog intenziteta, najčešće se u apodozi pojavljuje modalni glagol morati. Građa pokazuje da su podjednako zastupljeni primeri u kojima protazni deo kondicionalne konstrukcije prethodi apodoznom i oni u kojima apodozni deo prethodi protaznom:

[...] ako hoću da budem dobar bogoslov, moram najpre dobro i istinski da se molim (spc_n.txt); Ideološki možeš da ostaneš čist, a ako hoćeš da se baviš politikom moraš da zavučeš ruke do lakata u pogan i krv (kuldod00_n.txt); Kaže, ako hoćeš zdravo da se hraniš, bar jednom dnevno moraš jesti kašikom (poli080518.txt); Procedura je uspostavljena i, ako hoćemo da dodirnemo 'd' od demokratije, moramo da je poštujemo (rts080710.txt); [...] ali ako hoćemo da ljudi tamo ostanu, onda im moramo obezbediti da rade i zarade, da imaju kuće i struju, škole (poli080224.txt); Jer, ako hoćemo da živimo u demokratiji, moramo da prihvatamo rezultate izbora (poli070128.txt); [...] ako hoćemo da saznamo istinu o vremenu u kom živimo, moramo upoznati i jedne i druge (Flj-filo_n.txt); [...] ako hoćete da opstanete kao kreativna i zdrava ličnost, morate da stvorite mali „džep” za sebe (poli101202.txt); U Samari su odlučili da njima pripadne ekskluzivno pravo na „Žigulovskoje” a drugi, ako hoće i dalje da ga proizvode, moraju za to da plate (poli000821.txt); Svaki seljak, ako hoće da opstane, onda mora da zna bar 15 zanata, seljaci sve znaju da rade (rts090222.txt); No, kako sada stvari stoje, ako hoće da putuju u Berlin ili Barselonu, moraće dugo da čekaju u redovima ne bi li dobili vizu (poli081204.txt).

Bilo bi lepo da se iskoreni to verovanje u našem narodu, da moraš da ukradeš biljku ako hoćeš da ti bude lepa (poli090312.txt); Moraš nešto da izmisliš, ako hoćeš da zaradiš (rts080923.txt); kako ja vidim stvari moramo da pobedimo u svim mečevima ako hoćemo da prođemo dalje 
(rts090614.txt); Moramo svi da se žrtvujemo ako hoćemo da sačuvamo Zemlju (poli100106.txt); [...] ali moramo da budemo jedinstveni ako hoćemo na najbrži mogući način da poboljšamo ambijent $u$ košarci (poli080302.txt); [...] moramo da požurimo ako hoćemo da uspostavimo potpunu kontrolu političkih partija nad institutima (poli100322.txt); Morate biti spremni da sarađujete sa neprijateljima ako hoćete da se okonča pobuna (rts100129.txt); [...] mora da dolazi na rehabilitaciju ako hoće da izleči nogu (poli060815.txt); [...] savetovao joj da mora da bude staložena ako hoće da postane predsednik (poli070504.txt); [...] zatvorenici u njegovom zatvoru u okrugu Marikopa moraju da vrte pedale ako hoće da gledaju televiziju (rts100409.txt).

Slabiji intenzitet podsticaja iskazuje se glagolom trebati, koji je takođe frekventan u građi. I u ovim primerima registrovane su obe mogućnosti redosleda klauza:

[...] ako hoćemo da opstanemo, treba da prepoznajemo glasove naših prethodnika kao naše savremenike (kuldod02_n.txt); [...] ako hoćemo nešto dopadljivo i slatko, onda treba da kupimo „milka” čokoladu (poli101127.txt); [...] da je vlada kao i mlada nevesta: ako hoće dobro da se uda, treba najpre da se dopadne mladoženji pa tek onda komšiluku (republika316.xml).

Stručnjaci kažu da sa pripremama treba početi deset godina pre penzionisanja, ako hoćemo da izbegnemo mnoge neželjene pojave (poli080828.txt); [...] parlament treba da bude mesto u kome se neguje kultura dijaloga, ako hoćemo da nas građani poštuju (poli071029.txt); U našoj sredini Kopaonik već godinama važi za mesto gde obavezno treba otići ako hoćete da okolini date do znanja da ste „neko i nešto” (svt225_n.txt).

S ovim značenjem, ali daleko manjom frekvencijom, zabeležen je i glagol valjati:

[...] učiš šta mu valja besjediti i s koje strane, ako hoćeš da te sluša, ako hoćeš da budeš narodan književnik (Danicic.xml); Sve ove događaje koji su potresali stari svet valja imati u vidu ako hoćemo da pravedno ocenimo poslednjeg velikog astronoma aleksandrijskog Klaudija Ptolemaja (carstvo_n.txt). 
Neophodnost, nužnost, potreba da se izvrši situacija imenovana u apodozi iskazuje se i priloškim predikatima tipa: neophodno je, nužno je, potrebno je:

Zmijski jezik, jezik mržnje, kritike, osude, neophodno je, o kojem govori Maršal Rozenberg, zameniti ,jezikom saosećanja”, razumevanja i poštovanja, ako hoćemo da konstruktivno rešavamo sukobe (poli090926.txt); Ja sam tvrdo uveren da je svakom narodu, ako hoće da je narod, nužno da se razvija ne samo u jednom pravcu, već raznostruko, u svim granama nauke (kuldod01_n.txt); [...] ako hoćemo da nastavimo stvaranje modernog kluba, potrebno je da svi segmenti funkcionišu brže (rts101106.txt).

Takvu semantiku imaju i predikati s pridevima u leksičkom jezgru, tipa: neophodan je, potreban je:

[...] kazna je neophodna u vaspitanju ako hoćemo da od deteta bude „,dobar čovek", smatraju Srbi (pr_o_det.txt); [...] ako hoćemo da se spasemo kao narod, svuda su nam potrebni dobri domaćini (poli090929.txt).

U apodozi se pojavljuju i glagoli podsticaja, kao što su: savetovati, predlagati, prisiljavati i sl. Njima se iskazuje delovanje na nečiju volju, mobilisanje nekoga na akciju: ${ }^{2}$

Posle toga i tužilac i advokat oštećenog lica su mi savetovali da napustim Kanadu ako hoću da preživim (poli070101.txt); Ipak, savetujem mu, ako hoće da uspe, da ode u mesare ili automehaničare (svt225_n.txt); [...] $\underline{\text { ako }}$ hoće i dalje da razgovaraju, mi predlažemo da najpre deblokiraju pregovore (rts090521.txt); [...] Grci koji su mu predložili da se moli svetom Vartolomeju ako hoće da dobiju dete . (poli060509.txt); Ovaj dobrovoljni otkup pšenice prisiljava sve seljake da svojevoljno, ako hoće da žanju žito, ulože po 10.750 dinara po zasejanom jutru i da ih poklone državi i narodu (poli091224.txt).

Neretko se u funkciji apodoznog predikata pojavljuje imperativ, kojim se iskazuju različiti intenziteti i tipovi podsticaja, koji kao govorni činovi pripadaju zahtevu, savetu, preporuci i sl.: ${ }^{3}$

\footnotetext{
${ }^{2}$ Oni se u literaturi označavaju terminima: inicijativno-komunikativni (Ivić, 1970: 46-47), prinudno-manipulativni (Batistić, 1978: 76), modalno-komunikativni (Radovanović, 1977: 110), performativni glagoli za iskazivanje imperativnosti (Piper, 2005: 661). Up. detaljnije o glagolima podsticaja kod D. Zvekić-Dušanović (2011: 162-178).
} 
Veruj narodu, ako hoćeš da narod veruje tebi (poli070118.txt); Kažu ljudi, ako hoćeš da se raduješ, da uživaš, onda dođi u Banat, u Kikindu, a za ostalo će se pobrinuti domaćini (poli061011.txt); Ako hoćeš da ideš iz zemlje - nauči engleski, ako hoćeš da ostaneš - nauči kineski (rts101102.txt); Ako hoćeš da uradiš nešto dobro za godinu dana - posej kukuruz; ako hoćeš za 10 godina - posadi voćku; ako pak hoćeš za 100 godina - školuj ljude (poli100223.txt); [...] ako hoćemo da budemo i domaćini nesvrstanima - onda razmislimo koliko je mudar ovaj potez (poli090601.txt); [...] ako hoćete da dobro jedete, kupujte akcije, a ako hoćete mirno da spavate, kupujte državne papire (poli010708.txt); Priznajte Kosovo, ako hoćete u Evropu (poli080827.txt).

Vrednost imperativa, ukoliko se odnosi na 3. lice, ima konstrukcija neka + prezent:

[...] ako hoće izbore u decembru, neka podnese ostavku i eto parlamentarnih izbora (poli061107.txt); Neka dođe ako hoće još da me vidi (Mih_Tikv_n.txt); Pa, ako hoće da nas kontrolišu, neka plate (poli080915.txt).

U predikatu apodoze zabeleženi su i prezent i futur I, koji, u ovim kontekstima, imaju modalno značenje, tj. iskazuju šta treba raditi:

[...] kad si na moru pliva ti glava na vodi - ako hoćeš da je nalepšaš, veže se mašna (OlovkaPiseSr.xml); [...] ako hoćeš da menjaš društvo - onda se baviš politikom (poli090117.txt); Obnavljaš lekciju dok ne utvrdiš gradivo, ako hoćeš prelaznu ocenu, inače ponavljaš ili te izbace (nin0203_n.txt); Stoga kod mojih sugrađana vlada mišljenje da, $\underline{\text { ako }}$ hoćemo porodičnu harmoniju, dobru majku i pedantnu suprugu, oženimo Srpkinju (poli010429.txt); Angažovaće najstručnije ljude iz te oblasti, $\underline{\text { ako }}$ hoće dobar zakon (poli101024.txt).

${ }^{3}$ O govornim činovima, tipovima i jačini ilokutivnog napona direktivnih iskaza up. Lj. Popović (2005: 1021-1038). O ilokucionoj funkciji apodoznih predikata kondicionalnih konstrukcija govori i V. Hrakovski: „The illocutionary function of prescriptive MCs is to transmit the speaker's prescription (command, advice, request, etc.) for the performer (mostly, the listener) to implement the action described" (Xrakovskij, 2005: 14). 
1.2. Apodoznim predikatom može se iskazivati i zabrana, odnosno potreba da se ne vrši imenovana situacija. Podsticaj za neizvršavanje situacije ostvaruje se negiranim glagolom trebati:

Treba se lečiti od slabosti i mekuštva. I ako hoćeš da to postigneš, ne treba ponavljati svakog dana: „Ah, kako mi je teško” (Dosljaci-sve.xml); [...] dobacio je za radnom večerom nemačkoj kancelarki Angeli Merkel da „ne treba previše da pritiska ako hoće da uspe” (poli101113.txt).

Negirani glagol moći takođe nosi značenje zabrane, odnosno saveta da se ne vrši radnja imenovana njegovom dopunom ukoliko se želi ostvarivanje radnje protaze:

[...] ako hoćeš nešto konkretno da kažeš, ne možeš ostati na nivou poezije (varia.txt); [...] ako hoćemo da gradimo pravnu državu, onda se dogovori ne mogu praviti mimo pravnih institucija (poli080622.txt); [...] $\underline{\text { ako }}$ hoćete da napravite metropolu, ne možete primenjivati logiku palanke (poli081026.txt); Međutim, ni on neće moći mnogo da pobegne od programa radikala ako hoće da uzima njihove birače (poli080922.txt).

Zabrana se iskazuje i negiranim glagolom smeti:

To nije dobar znak i ne bi smelo da su u tom znaku nijedni izbori, ako hoćemo da budu pravi, istinski i demokratski (poli010419.txt); [...] dragocenu snagu, čiji nijedan delić ne sme utrošiti na užasavanje od rane ako hoće da je preživi ili da živi nekako i s njom (Sudbine_n.txt).

I negirani priloški predikat nije dozvoljeno nosi značenje zabrane:

I spoznajom da nam nije više dozvoljeno ni da volimo ni da saosećamo, ako hoćemo da budemo „dobri patrioti” (poli081025.txt).

Takvo značenje imaju i negirani imperativ i konstrukcija nemoj $+d a+$ prezent:

Ruse ne pominji ako hoćeš da izvučeš bar mršavu dvojčicu (poli091213.txt); [...] ako hoćeš da budem potpuno mirna s one strane groba, nemoj da mučiš sebe, nemaj griže savesti, ne prebacuj (Dosljacisve.xml).

1.3. Evaluativnim predikatima tipa dobro je / nije dobro indirektno se utiče na akciju subjekta u smislu da treba / ne treba izvršiti datu situaciju: 
Relativno inteligentan čovek bi rekao, ako hoću Subotiću da učinim nešto, bolje je da nemamo nikakav kontakt, da naša veza ostane tajna (nin0201_n.txt); [...] ako hoćemo budućnost, a tamo je dobra sirovinska baza i mogla bi da se pokrene proizvodnja, onda je bolje naći strateškog partnera (poli100118.txt); Nije dobro ni da predsednik države, ako hoće da mu narod veruje, ne zna za izručenje bivšeg predsednika Hagu (poli010703.txt).

\section{Apodozni predikat sa značenjem mogućnosti}

2.1. Odluka za ostvarivanje situacije označene dopunom glagola moći zavisi od volje subjekta glagola hteti. Glagolom moći iskazuje se dozvola ili pravo na ostvarivanje situacije na osnovu izvesnih karakteristika ili moći govornika, pozicija u društvu, odgovarajućih kompetencija, sile zakona i sl. Primarno značenje „imati dozvolu” imaju sledeći primeri:

Čoveka u pećini dočeka glas da može da uzme te kamenčiće, ako hoće (poli061026.txt); [...] domaćini su ga upitali: „Možemo li i mi da radimo kao Japanci”? Odgovor je bio: „Možete ako hoćete” (poli010625.txt); [...] da Oznu ne interesuje njegova politička prošlost i zavrzlama oko Pečata i da može, ako hoće, sa prvim transportom da krene na kopno (republika308.xml); Jesi li sigurna da ne želiš da ga zadržišs? Ti znaš da možeš ako hoćeš (BB-zveri-s.xml); [...] među kojima su bile i jedne, crne, paradne, kočije. Pavle, ako hoće, može da ih upotrebljava (seobe2.txt); Nije ona više dete. Kapetan je može, ako hoće, poljubiti (seobe2.txt).

Dominantno značenje ,imati pravo" ilustruju primeri kao što su:

[...] niko ne može da ih natera da povećaju cene . - Možemo da prevozimo putnike i besplatno ako hoćemo (poli080306.txt); Na primer, mi možemo, ako hoćemo, doneti odluku da se znak pitanja izostavlja u upitnim rečenicama sa upitnom reči (ms-jezik_n.txt); Damčević u stanu odgaja piliće i svinje, dežurni inspektor je rekao da može da gaji i kravu ako hoće, jer je to njegovo privatno vlasništvo (poli090530.txt); Karić je rekao da „država može sve da uradi, i da zabrani rad ako hoće, to nije problem, vlast može sve" (poli010722.txt); Lekić bi u toj varijanti u skupštini ostao samo kao nezavisni poslanik, koji ako hoće, može da glasa za predloge PSS - a (poli060113.txt). 
Ima, upravo, i primera u kojima je ekspliciran modalni indikator imati pravo:

To nije kažnjivo, a i Ljajić i Vukčević imaju pravo da, ako hoće, kažu u lice Karli Del Ponte da vole Mladića do ludila (poli060927.txt); Svako ima pravo da se ženi, dvaput, triput, ako hoće i sto puta, ali mora svaki put da se razvede od prethodne žene (poli100121.txt).

Jedno od sredstava za iskazivanje dozvole jeste i modalni glagol smeti:

Smete odmah, ako hoćete, da radite sve što vam je korisno, da obrađujete zemlju, idete gde god hoćete, da napasate stoku (poli010527.txt); Hit je regulativa 2257 / 94 koja određuje koliko sme da bude zakrivljena banana ako hoće u EU . (poli070429.txt).

Dozvola se iskazuje i priloškim predikatom dozvoljeno je:

Guverner je rekao da je bankama dozvoljeno da, ako hoće, za petinu smanje nivo kredita u Srbiji (rts100226.txt).

Polazeći od pretpostavke da sagovornik želi ostvarivanje situacije, govornik može i imperativom davati saglasnost, dozvolu za njeno izvršenje:

[...] od volje ti je, ako hoćeš idi, ako nećeš ne moraš (zbornikFM_01.xml); A ja kažem, nazovi me ako hoćeš i testijom, samo me nemoj razbiti (kuldod01_n.txt); Krsti ga ako hoćeš i u adventističkoj crkvi, ali se neće zvati po mrtvim ljudima (romi-001_n.txt); Sa'rani me prvo, pa onda radi šta znaš. Dovedi, posle, Cigane da ti sviraju ako hoćeš (Mih_Tikv_n.txt); Vjeruj u crnog đavola ako hoćeš, samo ne zalazi po meni i ne traži da te slijedim (an-kovac.xml); Ti ćeš sa mnom i sa vojskom lađom iz Kopra, a posle se vrati, ako hoćeš (poli090718.txt).

Značenje dozvole, saglasnosti ima i konstrukcija neka + prezent $\mathrm{u}$ sledećim primerima:

A može da dođe kad hoće. Eto sutra, ako hoće, neka dođe (tasana.txt); Neka ide ako hoće. Njegova stvar (mo103012_n.txt); Neka se udaje, ako hoće (hasanagin.txt); Nisam hteo da podižem taj fašistički novac. Neka moji naslednici, ako hoće, uzmu kad ja umrem (poli080215.txt); [...] a ovi lopovi, ako hoće, neka kradu (poli070903.txt). 
Za iskazivanje dozvole i saglasnosti pojavljuje se i samostalno upotrebljena konstrukcija $d a+$ prezent. U tom slučaju modalni glagol moći implicitno je prisutan, može se dodati konstrukciji: ${ }^{4}$

- Je li to zbog Zorke? - progovori Stiković odjednom. - Pa, baš ako hoćeš, da govorimo i o tom. Jest, i zbog Zorke (na-Drini.txt); Odgovorio je da to ne dolazi u obzir, da uzmemo pare ako hoćemo, a ako nećemo, on će da ih vrati u Beograd (poli090206.txt); Dodik je, aludirajući na rukovodstvo SDS-a, poručio da ,veruju u to ako hoće” (poli071211.txt); Odande mu je stigao brzometan odgovor da ih tuži, ako hoće, nadležnom organu uprave (poli090403.txt).

2.2. Glagolom moći iskazuje se i sposobnost subjekta za ostvarivanje situacije označene dopunom. Izvor mogućnosti su njegove karakteristike. Tada je značenje ovog modalnog glagola „biti u stanju”:

Primer krađe skulpture sa Čukur - česme pokazuje kako lako policija

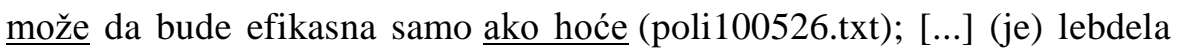
slika trenutno viđena u crkvi, i njoj se činjaše da može da je ponovo oživotvori, samo ako hoće (cosicb_2_n.txt); [...] sam sebe uverio da je zdrav, da može da se miče slobodno, da govori i da se smeje glasno, da peva ako hoće (na-Drini.txt); [...] ovaj pisac najčešće se bavio ratnom temom, osuđivao i radio ono što intelektualac može - ako hoće (poli080217.txt); Dragana Tomića najurili iz SPS, a zašto - to on najbolje zna - pa može da vam kaže, naravno ako hoće (poli010508.txt).

Uverenost govornika da će subjekat, ukoliko hoće, ostvariti situaciju, da je sposoban za to, može se iskazati i futurom I:

[...] oženićeš se ako hoćeš, a ako ne, ostaćeš gospodine, ipak za mene moj gospodin brat - zet (Afrika-lat.txt); [...] kazaće sama ako hoće (romi001_n.txt); Ako želiš, ako ti je potreban, $\underline{\text { ako hoćeš, ti ćeš ga naći }}$ (cosicb_2_n.txt).

2.3. Glagolom moći, kao što je to pokazano na prethodnim primerima, najčešće se označava mogućnost. Zabeleženi su, međutim, i primeri u kojima

\footnotetext{
${ }^{4}$ O konstrukciji $d a+$ prezent bez modalnih glagola up. Mrazović (2009: 188-189).
} 
govornik ovim glagolom označava svoju spremnost za izvršavanje situacije označene dopunom, ukoliko je sagovornik s tim saglasan, $\mathrm{tj}$. ukoliko je to $\mathrm{u}$ skladu s njegovom voljom:

[...] ako hoćete, mogao bih da odem na prugu, do kraja decembra dobrovoljno da radim, šta bilo (an-isakovi.xml); [...] sudija postaje već i malo nervozan. „Pa, ne znam, ali, ako hoćete, ja sve te provjere mogu da izvršim do sljedećeg ročišta" (lausevic.xml); Vi bi sigurno da vidite da li je na lađi; ako hoćete, možemo priterati sasvim blizu (SaSilamaNe.xml); [...] čuo sam da su se u međuvremenu venčali, ili još malo kasnije, možemo da proverimo u dokumentima ako hoćete - i poče da ustaje (romi-002_n.txt).

U sledećim primerima spremnost govornika da ostvari imenovanu situaciju iskazana je futurom I:

Čekaću te ako hoćeš (rastk01_n.txt); Nećemo raditi kao drugi poslednjih godina, sačekaćemo i, ako hoćete, normalne finansijske uslove (poli010218.txt); Javiću, ako hoćete, da donese puno mašni (anbulato1.xml).

Saglasnost, spremnost govornika da ispuni volju subjekta protaznog dela kondicionalne konstrukcije postiže se i različitim leksičkim sredstvima: glagolom pristajati, pridevom gotov, skraćenicom $O K$ i sl.:

[...] pristajem čak i da ostanem tamo, da vam budem metresa, - reče gorko - ako hoćete (crnj-kap.xml); Gotov sam, ma šta o meni mislili, da odem ne samo iz vašeg kvarta, nego i iz Beograda, ako hoćete (Dosljacisve.xml); Palo je nekoliko cigala i na moje prozore, ali ako hoćete, ja sam i bez toga gotov da idem (crnj-kap.xml); Hoćeš da odemo u šetnju? [...] $\underline{\text { OK}}, \underline{\text { ako hoćeš }}$ (romi-001_n.txt); [...] ako hoćeš tim tonom da razgovaraš, ok, mogu i ja, pomisli (romi-002_n.txt).

\section{ZAKLJUČAK}

U radu je prikazan jedan tip kondicionalnih konstrukcija, koji karakteriše realizacija modalnog glagola hteti u protazi. Ustanovljeno je da se, u tom slučaju, u velikom procentu i u apodozi ostvaruje neki od modalnih indikatora. Analiza je pokazala da se apodozni modalni markeri mogu podeliti u dve kategorije: 1) one kojima se iskazuju različite vrste podsticaja, i 2) one u kojima je zastupljeno značenje mogućnosti. Podsticaji različitih jačina i tipova iskazuju se: modalnim 
glagolima morati, trebati i valjati; predikatima s leksičkim jedinicama koje sadrže semantiku nužnosti, neophodnosti, potrebe i sl.; imperativom i modalno upotrebljenim prezentom i futurom. Sa značenjem zabrane pojavljuju se negirani glagoli trebati, moći i smeti, leksička sredstva i negirani imperativ. U okviru značenja mogućnosti izdvojeni su podtipovi: dozvola subjektu da ostvari željenu situaciju, sposobnost subjekta za izvršavanje situacije i spremnost govornika da udovolji želji subjekta protaznog predikata. Najfrekventniji modalni pokazatelji mogućnosti u apodozi su: modalni glagoli moći i smeti, imperativ, konstrukcija da + prezent, futur I i različita leksička sredstva.

\section{Dušanka Zvekić Dušanović}

\section{CONDITIONAL CONSTRUCTIONS WITH CONJUNCTION AKO AND VERB HTETI IN PROTASIS}

\section{Summary}

The paper analyses conditional sentences with the conjunction ako in which a complex predicate with the modal verb hteti appears as the predicate of the protasis. In such sentences, the apodotic predicate is often modally marked, and it contains modal constructions, which: 1) describe an action one must or should perform before they perform a desired one, or 2) express the possibility of carrying out the desired situations. The means for expressing these apodotic predicates can be typical representatives of the meaning of necessity (the verb morati: ako hoće $X$, mora $Y$ ) and possibility (the verb moći: ako hoće $X$, može $X$ ). The language units expressing the stimuli of different strengths and types include the modal verbs morati, trebati and valjati; predicates with lexical units containing the semantics of requisiteness, necessity, need, etc.; and imperative and modally used present and future tenses. The negative verbs trebati, moći and smeti; lexical instruments; and negative imperative carry the meaning of forbidding, which means a stimulus not to carry out the named action. Within the meaning of the possibility, the following subtypes can be isolated: permission for the subject to carry out a desired situation, a subject's ability to carry out the situation, and a speaker's readiness to satisfy the wish of the protatic predicate's subject. The most frequent apodotic modal ability indicators are the modal verbs moći and smeti, the imperative, $d a+$ present tense, future I, and various lexical instruments.

Key words: the Serbian language, conditional constructions, conditional clauses, conjuction ako, modality, modal verbs. 


\section{IZVOR}

Korpus savremenog srpskog jezika (www.korpus.matf.bg.ac.rs/korpus/login.php)

\section{LITERATURA}

Batistić, T. (1978). O nekim aspektima analize kauzativnih glagola. Južnoslovenski filolog XXXIV, 59-87.

Ivić, M. (1970). O upotrebi glagolskih vremena u zavisnoj rečenici: prezent u rečenici s veznikom da. Zbornik Matice srpske za filologiju i lingvistiku XIII/1, 43-54. (originalni rad objavljen ćirilicom)

Ivić, M. (2008). Lingvistički ogledi. Beograd: Biblioteka XX vek.

Kovačević, M. (2013). Rečenice s realnouslovnim veznicima u savremenom srpskom jeziku. Radovi Filozofskog fakulteta, Filološke nauke, 15/1, 931. (originalni rad objavljen ćirilicom)

Moskovljević Popović, J. (2018). O zavisnosloženim rečenicama sa komentativnom kondicionalnom klauzom. Južnoslovenski filolog 74, sv. 1-2, u štampi. (originalni rad pisan ćirilicom)

Mrazović, P. (2009). Gramatika srpskog jezika za strance. Sremski Karlovci Novi Sad: Izdavačka knjižarnica Zorana Stojanovića.

Piper, P. (2005). Semantičke kategorije u prostoj rečenici: Sintaksička semantika. U: Piper, P., Antonić, I., Ružić, V., Tanasić, S., Popović, Lj., Tošović, B. (2005). Sintaksa savremenoga srpskog jezika, Prosta rečenica. Beograd Novi Sad: Institut za srpski jezik SANU - Matica srpska. (originalni rad objavljen ćirilicom)

Piper, P. - Klajn, I. (2013). Normativna gramatika srpskog jezika. Novi Sad: Matica srpska. (originalni rad objavljen ćirilicom)

Popović, Lj. (2005). Komunikativne funkcije proste rečenice. U: Piper, P., Antonić, I., Ružić, V., Tanasić, S., Popović, Lj., Tošović, B. (2005). Sintaksa savremenoga srpskog jezika, Prosta rečenica. Beograd - Novi Sad: Institut za srpski jezik SANU - Matica srpska. (originalni rad objavljen ćirilicom)

Radovanović, M. (1977). Imenica u funkciji kondenzatora (II). Zbornik Matice srpske za filologiju i lingvistiku XX/2, 81-160.

RSJ (2007). Rečnik srpskoga jezika. Novi Sad: Matica srpska. (rečnik je pisan ćirilicom)

Stanojčić, Ž. - Popović, Lj. (2002). Gramatika srpskoga jezika. Beograd: Zavod za udžbenike i nastavna sredstva. (originalni rad objavljen ćirilicom) 
Zvekić-Dušanović, D. (2011). Modalnost: motivaciona modalnost u srpskom $i$ mađarskom jeziku. Novi Sad: Filozofski fakultet.

Xrakovskij, V. (ed.) (2005). Typology of Conditional Constructions. München: Lincom Europa. 